\title{
Association studies between $-1185 A / G$ von Willebrand factor gene polymorphism and coronary artery disease
}

D. Simon ${ }^{1}$, C.A. Paludo ${ }^{1}$, G.C. Ghisleni ${ }^{1}$, W.C. Manfroi ${ }^{2}$ and I. Roisenberg ${ }^{1}$
${ }^{1}$ Departamento de Genética, Instituto de Biociências, and 2Serviço de Cardiologia, Hospital de Clínicas de Porto Alegre, Faculdade de Medicina, Universidade Federal do Rio Grande do Sul, Porto Alegre, RS, Brasil

\section{Correspondence \\ I. Roisenberg \\ Departamento de Genética \\ Instituto de Biociências, UFRGS \\ Caixa Postal 15053 \\ 91501-970 Porto Alegre, RS \\ Brasil \\ Fax: +55-51-3316-7311 \\ E-mail: israberg@ufrgs.br}

Research supported by FINEP

(No. 66.96.0617.00) and PRONEX

(No. 76.97.0996.00). C.A. Paludo

is the recipient of a CNPq

fellowship. The present address of

D. Simon is Universidade Luterana

do Brasil, Canoas, RS, Brasil.

...................

Received June 14, 2002

Accepted March 27, 2003

\begin{abstract}
High levels of von Willebrand factor (vWF) have been associated with cardiovascular disease. The A allele of the $-1185 \mathrm{~A} / \mathrm{G}$ polymorphism in the 5'-regulatory region of the vWF gene was associated with the highest plasma vWF levels in a normal population. To examine the association between $-1185 \mathrm{~A} / \mathrm{G}$ polymorphism and coronary artery disease (CAD), 173 Brazilian Caucasian subjects submitted to coronary angiography were studied. Of these, 57 (33\%) had normal coronary arteries (control group) and $116(67 \%)$ had CAD (patient group). Plasma vWF levels were higher in patients $(145 \mathrm{U} / \mathrm{dl})$ than in controls $(130 \mathrm{U} / \mathrm{dl})$, but the differences were significant only for $\mathrm{O}$ blood group subjects. Polymerase chain reaction amplification of the 864-bp vWF promoter region followed by AccII restriction digestion was used to identify the $-1185 \mathrm{~A} / \mathrm{G}$ genotypes. The $-1185 \mathrm{~A}$ allele frequency was $43.1 \%$ in patients and $44.7 \%$ in controls. Allele and genotype frequencies were not significantly different between patients and controls. No association was observed between the $-1185 \mathrm{~A} / \mathrm{G}$ genotypes and plasma vWF levels in patients or controls. These results suggest that $-1185 \mathrm{~A} / \mathrm{G}$ polymorphism is not an independent risk factor for CAD.
\end{abstract}

Key words

- von Willebrand factor

- Coronary artery disease

- DNA polymorphisms

- Risk factor

\section{Introduction}

von Willebrand factor (vWF) is a multimeric glycoprotein serving as a carrier protein for coagulation factor VIII, and is involved in platelet adhesion and aggregation at the site of vessel wall injury. vWF-mediated platelet adhesion and thrombus formation are crucial under conditions of high shear stress such as those found in small blood vessels and in stenotic arteries. High levels of vWF have been associated with cardiovascular disorders such as ischemic heart disease, peripheral and pulmonary vascular disease, cerebrovascular disease, left ventricular aneurysm, atrial fibrillation, and deep venous thrombosis, as reviewed by Lip and Blann (1). Some studies have shown that high plasma vWF levels are a significant and independent predictor of cardiovascular risk in subjects with coronary artery disease (CAD) (2-11), but few studies have exam- 
ined the relationships between vWF genotypes and coronary heart disease (12-16).

Four single nucleotide polymorphisms (SNPs) in the 5'-regulatory region of the vWF gene have been recently associated with plasma vWF levels in a normal population $(17,18)$. These polymorphisms are in strong linkage disequilibrium and are segregated in two distinct haplotypes. For one of these SNPs, the $-1185 \mathrm{~A} / \mathrm{G}$ polymorphism, AA homozygotes were significantly associated with the highest vWF levels, GG homozygotes showed the lowest levels, and heterozygotes showed intermediate levels (17). Thus, the $-1185 \mathrm{~A}$ allele would be expected to be associated with an increased incidence of $\mathrm{CAD}$ and to constitute a risk factor.

The aims of this study were to evaluate the frequencies of the $-1185 \mathrm{~A} / \mathrm{G}$ genotypes and alleles in Caucasian patients with CAD and controls and to examine the association of this polymorphism with CAD and with plasma vWF levels.

\section{Subjects and Methods}

A total of 183 consecutive and unrelated Brazilian Caucasian individuals admitted for routine angiography, for investigation of chest pain and/or suspected CAD were recruited for the study from the Hemodynamics Service of the Hospital de Clínicas de Porto Alegre (Rio Grande do Sul, Brazil) over a period of nine months (March through November 1998). Subjects who had had a myocardial infarction in the 30 days before the investigation were excluded from the study. Individuals with angiography-proven $\geq 50 \%$ stenosis in a major coronary artery or one of their branches constituted the CAD group (116 individuals) and those without any angiographically detectable lesion constituted the control group (57 individuals). Ten subjects with $>10$ and $<50 \%$ stenosis were excluded from the analysis.

All subjects gave written informed con- sent to participate in the study. All individuals completed a standard questionnaire concerning their personal history and the Institutional Ethics Committee of the Hospital de Clínicas de Porto Alegre approved the study protocols.

Individuals reporting regular smoking during the last five years were considered to be smokers. Hypertension was defined as present if mean blood pressure was higher than $160 / 90 \mathrm{mmHg}$, or if the patient was already under treatment with antihypertensive drugs at inclusion. Diabetes mellitus was diagnosed as present if the fasting blood glucose level was $\geq 126 \mathrm{mg} / \mathrm{dl}$ or if the individuals were on treatment with insulin or other antidiabetic agents at the time of inclusion. Dyslipidemia was defined by levels of triglycerides $\geq 160 \mathrm{mg} / \mathrm{dl}$, HDL cholesterol $<40 \mathrm{mg} / \mathrm{dl}$ and LDL cholesterol $>100 \mathrm{mg} / \mathrm{dl}$, or if the individual was receiving lipid-lowering treatment at inclusion. Overweight or obesity was defined as BMI $\geq 26 \mathrm{~kg} / \mathrm{m}^{2}$.

High-molecular weight DNA was extracted from whole blood using a nonenzymatic technique for DNA analysis (19). A 864-bp fragment was amplified by the polymerase chain reaction (PCR), as previously reported (20). DNA fragments were prepared with the AccII restriction enzyme, separated by electrophoresis on $1 \%$ agarose gel containing ethidium bromide, and visualized under ultraviolet light. In the absence of a cleavage site, AccII digestion yielded one 864-bp band (the A allele), while the presence of a cleavage site resulted in 668- and 196-bp bands (the G allele).

Plasma vWF antigen (vWF:Ag) was quantified by immunoelectrophoresis using a polyclonal rabbit antihuman vWF antibody (21). All assays were performed at two different plasma dilutions. Pooled human plasma from 20 normal donors was considered to contain 100 U/dl vWF:Ag. Plasma vWF:Ag levels were reported as $\mathrm{U} / \mathrm{dl}$ relative to the level in the normal plasma pool.

Allele frequencies were determined by 
direct count of the alleles. Departures from Hardy-Weinberg equilibrium and differences between groups were evaluated by the $\chi^{2}$ test. The skewness of the plasma vWF:Ag distribution was normalized by logarithmic (log) transformation, although for convenience, back-transformed means and 95\% confidence intervals are given in the tables. The unpaired Student $t$-test was used to compare age and vWF levels between patients and controls, and all other variables were analyzed by the $\chi^{2}$ test. Multiple linear regression analysis was used to assess the relationship between plasma vWF levels and CAD risk factors (smoking, diabetes mellitus, hypertension, dyslipidemia, overweight/ obesity, gender, age, and ABO blood group). Linear regression analysis was used to adjust plasma vWF levels for the effect of age and ABO. ANOVA was used to compare vWF levels between genotype groups in patients and controls. A P value $<0.05$ was considered to indicate statistical significance.

\section{Results}

The main characteristics of the patients and control subjects are shown in Table 1 . No significant differences were observed between patients and controls for some CAD risk factors (smoking, diabetes mellitus, hypertension and overweight/obesity), although patients were significantly older and there were more males and dyslipidemics in the patient group than in the control group.

The plasma vWF levels of patients and controls are shown in Table 2. Patients showed higher vWF levels than controls, but this difference was not significant. Plasma vWF levels differed significantly between $\mathrm{O}$ and non-O blood group individuals in both patients and controls (patients: $\mathrm{t}_{(114)}=2.54$, $\mathrm{P}=0.012$; controls: $\left.\mathrm{t}_{(55)}=2.79, \mathrm{P}=0.007\right)$. In an analysis carried out only with $\mathrm{O}$ blood group subjects, the patients had higher vWF levels than controls. Comparison between patients and controls only for subjects of
non-O blood groups did not show significant differences. Analysis of plasma vWF levels adjusted for effects of age and ABO blood group showed no significant differences between patients and controls.

Allele and genotype frequencies of $-1185 \mathrm{~A} / \mathrm{G}$ polymorphism in patients and controls are shown in Table 3. The observed

Table 1. Main characteristics of coronary artery disease patients and control subjects.

\begin{tabular}{lcc}
\hline & Patients $(\mathrm{N}=116)$ & Controls $(\mathrm{N}=57)$ \\
\hline Mean age (range) & $62.4(32-84)^{*}$ & $55.6(31-82)$ \\
Male sex & $75.0^{*}$ & 40.3 \\
Smoker (current or former) & 31.9 & 22.8 \\
Overweight/obesity & 69.0 & 59.7 \\
Hypertension & 78.4 & 71.9 \\
Diabetes mellitus & 16.4 & 12.3 \\
Dyslipidemia & $50.9^{*}$ & 31.6
\end{tabular}

Data are reported as percentages, except for age (years).

${ }^{*} P<0.05$ compared to controls (unpaired Student $t$-test for age, and $\chi^{2}$ test for other data).

Table 2. Plasma von Willebrand factor levels in coronary artery disease patients and control subjects.

\begin{tabular}{lllllr}
\hline Blood group & \multicolumn{2}{c}{ Patients $(\mathrm{N}=116)$} & & \multicolumn{2}{c}{ Controls $(\mathrm{N}=57)$} \\
\cline { 2 - 3 } & Mean & $95 \% \mathrm{Cl}$ & & Mean & $95 \% \mathrm{Cl}$ \\
\hline All subjects & 145.0 & $134.1-156.8$ & & 130.0 & $117.6-143.7$ \\
O blood group & $131.7^{*}$ & $118.5-146.4$ & & 108.7 & $99.0-119.3$ \\
Non-O blood group & 160.2 & $143.1-179.3$ & & 143.2 & $124.7-164.5$ \\
\hline
\end{tabular}

95\% Cl: 95\% confidence interval.

${ }^{*} \mathrm{P}<0.05$ compared to controls (unpaired Student $t$-test).

Table 3. Allele and genotype frequencies of $-1185 \mathrm{~A} / \mathrm{G}$ von Willebrand factor gene polymorphism in patients and control subjects.

\begin{tabular}{ccc}
\hline & Patients $(N=116)$ & Controls $(N=57)$ \\
\hline Allele & & \\
A & $100(43.1)$ & $51(44.7)$ \\
G & $132(56.9)$ & $63(55.3)$ \\
Genotype & & \\
AA & $21(18.1)$ & $16(28.1)$ \\
AG & $58(50.0)$ & $19(33.3)$ \\
GG & $37(31.9)$ & $22(38.6)$ \\
\hline
\end{tabular}

There were no statistically significant differences between allele frequencies or genotype frequencies ( $\chi^{2}$ test). Values in parentheses are percentages. 
genotype frequencies were in HardyWeinberg equilibrium in the patient group, but in the control group there was a deficiency of heterozygotes $(\mathrm{P}<0.05)$, probably owing to the relatively small group size. The $-1185 \mathrm{~A}$ allele frequency was $43.1 \%$ in patients and $44.7 \%$ in controls. No significant differences were detected in allele or genotype frequencies between patients and controls. There was no statistically significant association between the $-1185 \mathrm{~A} / \mathrm{G}$ genotypes and plasma vWF levels in either patients or controls. In spite of the absence of statistical significance, plasma vWF levels presented an increase in the same direction as observed by Keightley et al. (17), with AA homozygotes having the highest levels (Table 4). Analysis of the effect of $-1185 \mathrm{~A} / \mathrm{G}$ polymorphism and $\mathrm{ABO}$ blood groups on plasma vWF levels showed no significant interaction between them (patients: $\mathrm{F}=0.05, \mathrm{P}=$ 0.949 ; controls: $\mathrm{F}=0.47, \mathrm{P}=0.628$ )

In a multiple linear regression model, age and $\mathrm{ABO}$ blood groups were the only independent and significant predictors of plasma vWF levels. For each 5 years of increase in age there was a $10.2 \mathrm{U} / \mathrm{dl}$ increase in plasma vWF levels in patients and a $10.4 \mathrm{U} / \mathrm{dl}$ rise in plasma vWF levels in controls $(\mathrm{P}<0.001)$.

\section{Discussion}

Several gene polymorphisms of the hemostatic system are currently identified as risk factors for thrombosis and/or athero-

Table 4. Plasma von Willebrand factor levels according to -1185A/G genotype.

\begin{tabular}{|c|c|c|c|c|}
\hline \multirow[t]{2}{*}{ Genotype } & \multicolumn{2}{|c|}{ Patients ( $N=116$ ) } & \multicolumn{2}{|c|}{ Controls $(N=57)$} \\
\hline & Mean & $95 \% \mathrm{Cl}$ & Mean & $95 \% \mathrm{Cl}$ \\
\hline$A A$ & 160.6 & $126.3-204.2$ & 138.1 & $108.8-175.4$ \\
\hline$A G$ & 144.6 & $128.9-162.3$ & 124.0 & $105.3-146.0$ \\
\hline GG & 137.4 & $123.2-153.3$ & 129.6 & 110.3-152.2 \\
\hline
\end{tabular}

There were no statistically significant differences between patients and controls regarding $-1185 \mathrm{~A} / \mathrm{G}$ genotypes (unpaired Student $\mathrm{t}$-test). $95 \% \mathrm{Cl}$ : $95 \%$ confidence interval. sclerosis $(22,23)$. We assessed the potential association between CAD and the $-1185 \mathrm{~A} / \mathrm{G}$ polymorphism of vWF gene in Brazilian subjects submitted to coronary angiography. The main genetic variable known to be involved in vWF levels is the ABO blood system, that accounts for $30 \%$ of the genetic variance (24). Individuals of the $\mathrm{O}$ blood group have, on average, lower vWF levels than individuals of the non-O blood group (25-28). Our results agree with the well-documented relationship between the $\mathrm{ABO}$ blood system and vWF levels.

High vWF levels have been associated with CAD (2-11). In the present study patients showed higher plasma vWF levels than controls, but this difference was not significant. This may have been due to differences in frequencies of $\mathrm{ABO}$ blood groups between controls and patients, with an excess of $\mathrm{O}$ individuals in the patient group, at the limit of significance $(50.9 \%$ in patients versus $35.1 \%$ in controls: $\left.\chi^{2}=3.833, \mathrm{P}=0.05\right)$. Significant differences in plasma vWF levels were observed only in subjects of the $\mathrm{O}$ blood group, with patients having higher vWF levels than controls.

The $-1185 \mathrm{~A} / \mathrm{G}$ polymorphism is in strong linkage disequilibrium with three other polymorphisms $(-1792 \mathrm{C} / \mathrm{G},-1234 \mathrm{C} / \mathrm{T}$ and $-1051 \mathrm{G} / \mathrm{A})$ in the promoter region of the vWF gene. Due to this linkage disequilibrium, these polymorphisms segregate as two distinct haplotypes (18). The influence of these polymorphisms on CAD was analyzed in three studies. Heywood et al. (12) studied the $-1792 \mathrm{C} / \mathrm{G}$ and $-1051 \mathrm{G} / \mathrm{A}$ polymorphisms in patients with ischemic heart disease compared to age-matched control subjects. The $-1792 \mathrm{C} / \mathrm{G}$ polymorphism was suggested as a potential risk predictor for ischemic heart disease, but was not correlated with vWF levels. Tompkins et al. (13) analyzed patients with unstable angina and $\mathrm{ABO}-$ matched and age-matched control subjects. The analysis of the three vWF gene regulatory sequence polymorphisms, including the 
$-1185 \mathrm{~A} / \mathrm{G}$ polymorphism, showed no significant difference between the two groups, but high levels of plasma vWF were associated with unstable angina. Di Bitondo et al. (15) investigated the $-1185 \mathrm{~A} / \mathrm{G}$ and $-1051 \mathrm{G} / \mathrm{A}$ polymorphisms and the risk of myocardial infarction in a case-control study and found no association between them. Our results show that the allele frequencies of the $-1185 \mathrm{~A} / \mathrm{G}$ polymorphism do not differ significantly between patients and controls, indicating that there is no association between this polymorphism and CAD.

However, it should be noted that the statistical power to detect differences in the present study may be limited due to the small sample size of the control group. On the basis of the conflicting results of these stud- ies, it is possible to assume that the $-1185 \mathrm{~A} / \mathrm{G}$ promoter polymorphism can have some effect on plasma vWF levels, and consequently on acute coronary events, but this influence may be slight and perhaps restricted to some specific environment-genotype effect.

The findings of the present study indicate that the $-1185 \mathrm{~A} / \mathrm{G} v \mathrm{WF}$ gene polymorphism is not an independent risk factor for CAD in the Brazilian Caucasian population and that plasma vWF levels were not associated with $-1185 \mathrm{~A} / \mathrm{G}$ genotypes. Our data therefore are not consistent with the hypothesis that the $-1185 \mathrm{~A} / \mathrm{G} \mathrm{vWF}$ gene polymorphism is related to $\mathrm{CAD}$, although an influence on outcome, or a link with subtypes of coronary syndromes, cannot be ruled out.

\section{References}

1. Lip GY \& Blann AD (1995). von Willebrand factor and its relevance to cardiovascular disorders. British Heart Journal, 74: 580-583.

2. Jansson JH, Nilssin TK \& Johnson O (1991). von Willebrand factor in plasma: a novel risk factor for recurrent myocardial infarction and death. British Hearth Journal, 66: 351-355.

3. Meade TW, Cooper JA, Stirling Y, Howarth DJ, Ruddock V \& Miller GJ (1994). Factor VIII, ABO blood group, and the incidence of ischaemic heart disease. British Journal of Haematology, 88: 601-607.

4. Montalescot G, Ankri A, Vicaut E, Drobinski G, Grosgogeat $Y$ \& Thomas D (1995). Fibrinogen after coronary angioplasty as a risk factor for restenosis. Circulation, 92: 31-38.

5. Thompson SG, Kienast J, Pyke SDM, Haverkate F \& van de Loo JCW for the European Concerted Action on Thrombosis and Disabilities Angina Pectoris Study Group (1995). Hemostatic factor and the risk of myocardial infarction or sudden death in patients with angina pectoris. New England Journal of Medicine, 332: 635-641.

6. Catto AJ, Carter AM, Barrett JH, Bamford J, Rice PJ \& Grant PJ (1997). von Willebrand factor and factor VIII:C in acute cerebrovascular disease: relationship to stroke subtype and mortality. Thrombosis and Haemostasis, 77: 1104-1108.

7. Folsom AR, Rosamond WD, Shahar E, Cooper LS, Aleksic N, Nieto FJ, Rasmussen ML \& Wu KK (1999). Prospective study of markers of hemostatic function with risk of ischemic stroke. Circulation, 100: 736-742.

8. Rumley A, Lowe GDO, Sweetnam PM, Yarnell JWG \& Ford RP (1999). Factor VIII, von Willebrand factor and the risk of major ischaemic heart disease in the Caerphilly Heart Study. British Journal of Haematology, 105: 110-116.

9. Nielsen NE, Siegbahn A \& Swan E (2000). Markers of hypercoagulation and von Willebrand factor in postmenopausal women with unstable coronary artery disease. Discriminatory ability regarding unstable coronary artery disease and coronary atherosclerosis using receiver operating characteristics. Journal of Internal Medicine, 248:
151-158.

10. Sakai H, Goto S, Kim JY, Aoki N, Abe S, Ichikawa N, Yoshida M, Nagaoka Y \& Handa S (2000). Plasma concentration of von Willebrand factor in acute myocardial infarction. Thrombosis and Haemostasis, 84: 204-209.

11. Wiman B, Andersson $T$, Hallqvist J, Reuterwall C, Ahlbom A \& deFaire U (2000). Plasma levels of tissue plasminogen activator/ plasminogen activator inhibitor-1 complex and von Willebrand factor are significant risk markers for recurrent myocardial infarction in the Stockholm Heart Epidemiology Program (SHEEP) study. Arteriosclerosis, Thrombosis, and Vascular Biology, 20: 2019-2023.

12. Heywood DMH, Ossei-Gerning N \& Grant PJ (1997). Two novel polymorphisms of the von Willebrand factor gene promoter and association with ischaemic heart disease. Thrombosis and Haemostasis, 77 (Suppl): S375 (Abstract).

13. Tompkins K, Cameron C, Brady J, Raj S, Keightley A \& Lillicrap D (1999). Polymorphisms in the glycoprotein Ib $\alpha, \alpha 2$ integrin and von Willebrand factor genes: possible implications in platelet adhesion and acute coronary events. Blood, 94 (Suppl 1): 71B (Abstract).

14. Lacquemant C, Gaucher C, Delorme C et al. (2000). Association between high von Willebrand factor levels and the Thr789Ala vWF gene polymorphism but not with nephropathy in type I diabetes. Kidney International, 57: 1437-1443.

15. Di Bitondo R, Cameron CL, Daly ME, Croft SA, Steeds RP, Channer KS, Samani NJ, Lillicrap D \& Winship PR (2001). The -1185 A/G and -1051 G/A dimorphisms in the von Willebrand factor gene promoter and risk of myocardial infarction. British Journal of Haematology, 115: 701-706.

16. Dai K, Gao W \& Ruan C (2001). The Smal polymorphism in the von Willebrand factor gene associated with acute ischemic stroke. Thrombosis Research, 104: 389-395.

17. Keightley AM, Lam YM, Brady JN, Cameron CL \& Lillicrap D (1999). Variation at the von Willebrand factor (VWF) gene locus is associated 
with plasma vWF:Ag levels: identification of three novel single nucleotide polymorphisms in the VWF gene promoter. Blood, 93: 4277-4283.

18. Harvey PJ, Keightley AM, Lam YM, Cameron C \& Lillicrap D (2000). A single nucleotide polymorphism at nucleotide -1793 in the von Willebrand factor (VWF) regulatory region is associated with plasma WWF:Ag levels. British Journal of Haematology, 109: 349-353.

19. Lahiri DK \& Nurnberger Jr JI (1991). A rapid non-enzymatic method for the preparation of HMW DNA from blood for RFLP studies. Nucleic Acids Research, 19: 5444.

20. Simon D, Palatnik M \& Roisenberg I (2002). Analysis of the $-1185 \mathrm{~A} / \mathrm{G}$ von Willebrand factor (VWF) gene polymorphism in two Brazilian ethnic groups and its effect on plasma VWF levels. Thrombosis Research, 105: 519-522.

21. Fischer RR, Lucas EM, Pereira AMB \& Roisenberg I (1996). Preparation of a heterologous antiserum for the determination of von Willebrand factor in human plasma. Brazilian Journal of Medical and Biological Research, 29: 1641-1644.

22. Lane DA \& Grant PJ (2000). Role of hemostatic gene polymorphisms in venous and arterial thrombotic disease. Blood, 95: 15171532.

23. Franco RF \& Reistma PH (2001). Gene polymorphisms of the hae- mostatic system and the risk of arterial thrombotic disease. British Journal of Haematology, 115: 491-506.

24. Orstavik K, Magnus P, Reisner H, Berg K, Graham J \& Nance W (1985). Factor VIII and factor IX in a twin population. Evidence for a major effect of ABO locus on factor VIII level. American Journal of Human Genetics, 37: 89-101.

25. Gill JC, Endres-Brooks J, Bauer PJ, Marks Jr WJ \& Montgomery RR (1987). The effect of $A B O$ blood group on the diagnosis of von Willebrand disease. Blood, 69: 1691-1695.

26. Shima M, Fujimura Y, Nishiyama T, Tsujiuchi T, Narita N, Matsui T, Titani K, Katayama M, Yamamoto F \& Yoshioka A (1995). ABO blood group genotype and plasma von Willebrand factor in normal individuals. Vox Sanguinis, 68: 236-240.

27. Kamphuisen PW, Houwing-Duistermaat JJ, van Houwelingen HC, Eikenboom JCJ, Bertina RM \& Rosendaal FR (1998). Familial clustering of factor VIII and von Willebrand factor levels. Thrombosis and Haemostasis, 79: 323-327.

28. Souto JC, Almsay L, Muniz-Diaz E et al. (2000). Functional effects of the $\mathrm{ABO}$ locus polymorphism on plasma levels of von Willebrand factor, factor VIII, and activated partial thromboplastin time. Arteriosclerosis, Thrombosis, and Vascular Biology, 20: 2024-2028. 